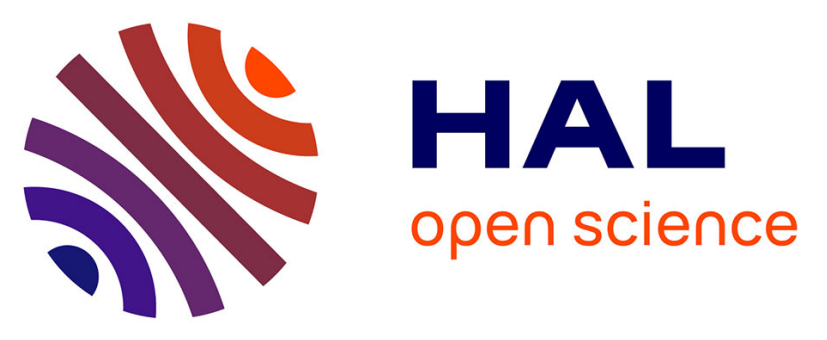

\title{
All-solid-state multimodal probe based on ISFET electrochemical microsensors for in-situ soil nutrients monitoring in agriculture
}

Matthieu Joly, Laurent Mazenq, Maurane Marlet, Pierre Temple-Boyer, Céline Durieu, Jérôme Launay

\section{To cite this version:}

Matthieu Joly, Laurent Mazenq, Maurane Marlet, Pierre Temple-Boyer, Céline Durieu, et al.. Allsolid-state multimodal probe based on ISFET electrochemical microsensors for in-situ soil nutrients monitoring in agriculture. 19th International Conference on Solid-State Sensors, Actuators and Microsystems (Transducers 2017), Jun 2017, Kaohsiung, Taiwan. 4p., 10.1109/TRANSDUCERS.2017.7994028 . hal-01871403

\section{HAL Id: hal-01871403 \\ https://hal.laas.fr/hal-01871403}

Submitted on 10 Sep 2018

HAL is a multi-disciplinary open access archive for the deposit and dissemination of scientific research documents, whether they are published or not. The documents may come from teaching and research institutions in France or abroad, or from public or private research centers.
L'archive ouverte pluridisciplinaire HAL, est destinée au dépôt et à la diffusion de documents scientifiques de niveau recherche, publiés ou non, émanant des établissements d'enseignement et de recherche français ou étrangers, des laboratoires publics ou privés. 


\title{
ALL-SOLID-STATE MULTIMODAL PROBE BASED ON ISFET ELECTROCHEMICAL MICROSENSORS FOR IN-SITU SOIL NUTRIENTS MONITORING IN AGRICULTURE
}

\author{
Matthieu Joly ${ }^{12}$, Laurent Mazenq ${ }^{1}$, Maurane Marlet ${ }^{2}$, Pierre Temple-Boyer ${ }^{1}$, Céline Durieu ${ }^{2}$, \\ and Jérôme Launay ${ }^{l *}$ \\ ${ }^{1}$ LAAS-CNRS, Toulouse, FRANCE and \\ ${ }^{2}$ Agronutrition, Carbonne, FRANCE
}

\begin{abstract}
We report the design of a silicon chip dedicated to the in-situ monitoring of soil nitrogen cycle in wheat crop. Our study shows that ion-sensitive field effect transistor (ISFET) microsensors are suitable for quick on-site or long-term analysis of nutrients measured directly in soil as opposed to soil extracts analysis. Our pH-ISFET recorded soil $\mathrm{pH}$ for six months with results in good accordance with standard sampling method and without any loss of sensitivity. The adaptation of pH-ISFET in $\mathrm{pNO}_{3}$ and $\mathrm{pNH}_{4}$-ISFET allowed, for the first time, the insitu measurements of natural variations of soil nitrogen contents caused by microorganisms' activity.
\end{abstract}

\section{KEYWORDS}

ISFET sensor; In-situ soil analysis; Multisensor probe; Ion-selective membrane; Nutrients levels determination; Agriculture;

\section{INTRODUCTION}

Feeding the world's population has huge climate and environmental impacts. New farming methods should be developed where fertilizers doses are determined over time at small scale according to soils variability. Conventional soil analysis methods are performed on soil samples by off-site laboratories which make them expensive and time consuming. Thus, our project aims to provide a low-cost, robust and real-time multimodal tool based on ISFET microsensors for in-situ monitoring of soil nutrients.

Since the 2000s, several studies showed the promising future of potentiometric sensors in precision agriculture. Most of them focus on the development of flow injection analysis (FIA) systems in which ionselective electrode (ISE) or ISFET are used for nutrients measurements in soil extracts performed on-site or onthe-go $[1,2]$. Futagawa et al. worked on the integration of $\mathrm{pH}$, temperature and electrical conductivity (EC) microsensors on a silicon chip for hydroponic applications [3]. Only Artigas et al. reported the fabrication of pH-ISFET, pK-ISFET, pCa-ISFET and pNO3-ISFET used directly in soil [4].

Nevertheless, more studies are needed to fully assess some important parameters of ISFET's detection capability in soil: influence of soil moisture, ISFET drift and lifetimes and the in-situ detection of other important nutrients like $\mathrm{NH}_{4}{ }^{+}$ammonium ions.

\section{EXPERIMENTAL}

\section{Microsensor fabrication}

Our microsystem is fabricated on 4-inch silicon substrates and composed of an ISFET, a miniature solidstate reference electrode, two platinum electrodes for EC measurements and a temperature sensor in MOSFET technology (fig.1).

$\mathrm{N}$-channel, normally-off pH-ISFET microsensors were fabricated using a 50nm silicon nitride $\mathrm{Si}_{3} \mathrm{~N}_{4} \mathrm{pH}-$ sensitive layer deposited by Low Pressure Chemical Vapor Deposition (LPCVD) on top of a 50nm thermal oxide $\mathrm{SiO}_{2}$ layer. Such ISFET was already studied in previous work, evidencing a quasi-Nernstian sensitivity around $50 \mathrm{mV} / \mathrm{pH}[5]$.

A silver/silver chloride quasi-reference electrode dedicated to quick on-site analysis was made using electrodeposition methods. We are currently working on a reference membrane with a good potential stability and small chloride concentration dependence. Our results, though, will not be shown in the present paper.

However, long-term measurement (at least a few months) with fully integrated microsystems in such a complex environment as soils is still a scientific challenge. One of the main reasons comes from the fact that no solid-state reference electrode displaying potential stability equivalent to macroscale and conventional reference electrode is so far available [6]. So, we also decided to assess the stability of a WE200 Silvion electrode, a macroscale reference electrode dedicated to permanent installation in soils.

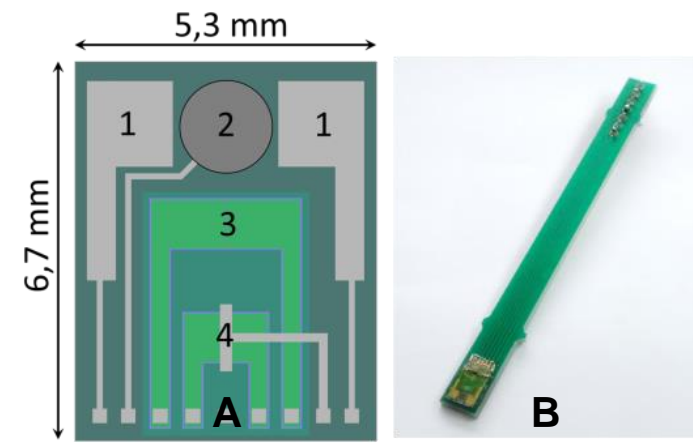

Figure 1: (A) Schematic top view of the microsystem. (1) Platinum electrodes for EC measurements; (2) Miniature $\mathrm{Ag} / \mathrm{AgCl}$ quasi-reference electrode; (3) ISFET microsensor; (4) MOSFET for temperature measurement. (B) View of the chip after electronic packaging on a printedcircuit board $(P C B)$ and encapsulation.

The detections of ammonium and nitrate ions were allowed by casting an ion-sensitive membrane on top of the pH-ISFET $\mathrm{Si}_{3} \mathrm{~N}_{4}$ layer. It is composed of a fluoropolysiloxane (FPSX) polymer matrix purchased from Dow Corning (730 FS) and sonicated in tetrahydrofuran with ionophores and ionic additives (Table 1). The FPSX matrix was chosen for its good 
adhesion properties on $\mathrm{Si}_{3} \mathrm{~N}_{4}$ surface leading to an improved sensor's lifetime [7].

Table 1: Membrane composition of $\mathrm{pNH}_{4-}$ and $\mathrm{pNO}_{3-}$ ISFET (\% weight).

\begin{tabular}{|c|c|c|c|}
\hline & Matrix & Ionophore & Ionic additives \\
\hline pNH4- & $\begin{array}{c}\text { FPSX } \\
\text { ISFET }\end{array}$ & $\begin{array}{c}\text { Nonactin } \\
(95.0 \%)\end{array}$ & $\begin{array}{c}\text { K-t-4ClPB } \\
(1.5 \%)\end{array}$ \\
\hline pNO3- & $\begin{array}{c}\text { FPSX } \\
(97.6 \%)\end{array}$ & $\begin{array}{c}\text { Nitrate } \\
\text { ionophore V } \\
(1.5 \%)\end{array}$ & $\begin{array}{c}\text { TDMAC } \\
(0.9 \%)\end{array}$ \\
\hline
\end{tabular}

\section{Electrochemical measurements}

The performances of the ISFETs were examined using a specific potentiometric ISFET-meter electronic interface with drain voltage $V_{d s}$ and current $I_{d}$ fixed to $2.0 \mathrm{~V}$ and $0.1 \mathrm{~mA}$ respectively. A multi-channel potentiostat, VMP3 from BioLogic Science Instruments, was used to measure the open-circuit potential of Silvion reference electrode. A silver silver chloride double junction electrode purchased from Metrohm was used as a reference electrode in aqueous solution and in soils. Sensitivity and selectivity tests were performed by increasing the activity of the primary ions using a $0.1 \mathrm{M}$ ammonium nitrate $\mathrm{NH}_{4} \mathrm{NO}_{3}$ aqueous solution. Selectivity coefficients were obtained with the Fixed Interference Method (FIM). We made sure that ISFETs exhibited quasi-Nernstian behavior in order to fulfil the IUPAC recommendations [8]. Measurements in soils were done by inserting the ISFET's PCB directly into the soil in a way that the sensitive part of the sensor was in close contact with the soil. All measurements were carried out at room temperature.

\section{RESULTS AND DISCUSSION \\ In-situ detection of soil $\mathrm{pH}$}

We first studied the detection capability of $\mathrm{pH}$-ISFET microsensors inserted directly into the soil in order to prove the feasibility of a direct measurement method as opposed to soil extract analysis.

Two silty-clay soils were first analyzed according to the standard method where a glass $\mathrm{pH}$ electrode is used in a $20 \mathrm{vol} \%$ suspension of soil in water. It led to $\mathrm{pH}$ values of 4.7 and 8.4. After a three points-calibration in $\mathrm{pH}$ buffer solutions ( $\mathrm{pH} 4,7$ and 10), quick in-situ measurements of pH-ISFET were recorded for both soils at different soil moisture levels (fig.2). The results are in great accordance with the standard method. Indeed, the maximum error was only $0.5 \mathrm{pH}$ unit and there was no correlation with soil moisture. In-situ measurements were even possible at soil relative water content of $40 \%$ which is below typical wheat growths conditions. With its small measurement errors relative to an agriculture application and its robustness, $\mathrm{pH}$-ISFET is fully compatible for quick on-field $\mathrm{pH}$ determination. In comparison, the more classical glass $\mathrm{pH}$ electrode used in field conditions can easily lead to measurements issues due to a clogged reference junction or a break of the glass bulb.

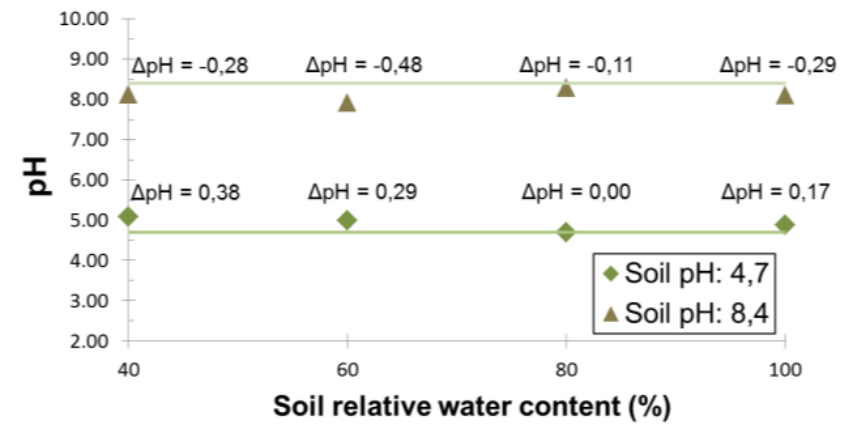

Figure 2: Comparison of pH measurements performed by pH-ISFET at different soil moisture levels in an acid and a basic silty-clay soil. The difference with the standard method of soil pH determination (green lines) is indicated above each measurement point.

Furthermore, we recorded for six months the signal drift of two pH-ISFET directly inserted in pots of siltyclay soil using the simple packaging showed on fig.1. This study aimed at assessing the pH-ISFET lifetime in soil to know if a monitoring during all wheat growth stages could be possible. Relative water content $(75 \%)$ was kept constant thanks to a daily subirrigation. Both microsensors displayed a linear $\left(\mathrm{R}^{2} \geq 0.87\right)$ and relatively small drift ( $<0.6 \mathrm{mV} /$ day) (fig.3). The ageing of $\mathrm{pH}-\mathrm{ISFET}$ caused by soil environment was evaluated by a comparison of their sensitivity before and after the experiment. Both ISFET kept their initial sensitivity $(51 \mathrm{mV} / \mathrm{pH})$.

We operated the same study on Silvion reference electrode (fig.3). As expected, the open-circuit voltage evolution in time showed a linear $\left(\mathrm{R}^{2}=0.92\right)$ and small drift $(0.11 \mathrm{mV} /$ day).

Thus, our pH-ISFET showed a lifetime in soil of at least six months and we identified a suitable reference electrode making the project of a long-term monitoring of soil nutrients possible.

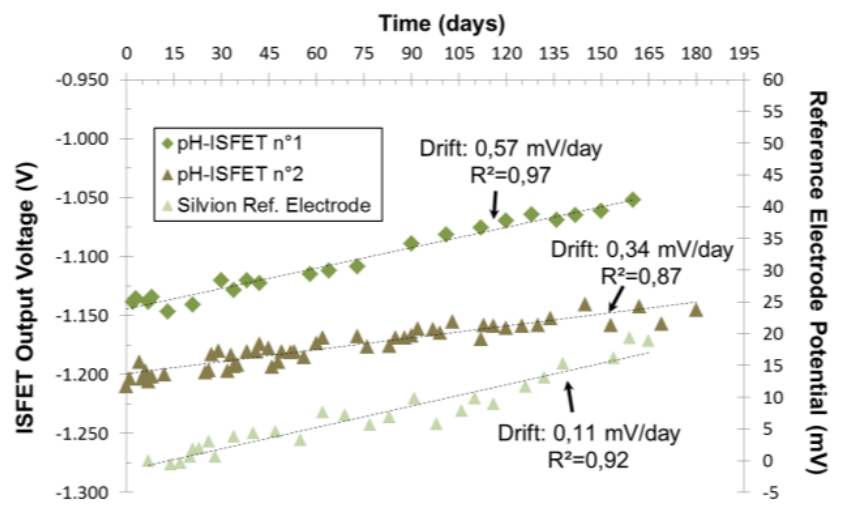

Figure 3: Time evolution of the potential of two $\mathrm{pH}$ ISFET (left y-axis) and a Silvion reference electrode (right y-axis) inserted for six months in a silty-clay soil. $\mathrm{An} \mathrm{Ag} / \mathrm{AgCl}$ glass double junction reference electrode was used during the measurements.

In-vitro detection of nitrate and ammonium ions Analytical responses and calibration curves obtained for $\mathrm{pNO}_{3}-$ and $\mathrm{pNH}_{4}$-ISFET are shown in fig.4, 5 and 6. 
Both sensors exhibited a linear response to the concentration of primary ions with a quasi-Nernstian sensitivity of $59.0 \mathrm{mV} / \mathrm{pNH}_{4}$ and $56.2 \mathrm{mV} / \mathrm{pNO}_{3}$, respectively. The limits of detection (LOD) calculated as recommended by IUPAC from the intersection of the two extrapolated segments of the calibration curve, were $3.2 \mu \mathrm{M}$ and $17 \mu \mathrm{M}$, respectively. Both the LOD and the linear range are in accordance with standard values of mineral nitrogen in field conditions. The main detection characteristics are summarized in Table 2 which shows that our probe should meet the requirements for a soil study application.

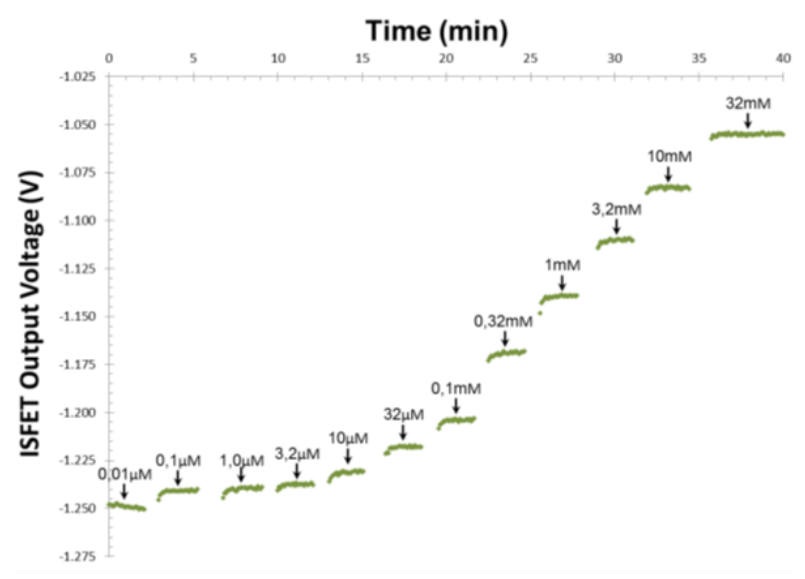

Figure 4: Analytical response of the $\mathrm{pNO}_{3}$-ISFET to the increase of $\mathrm{NH}_{4} \mathrm{NO}_{3}$ concentration.

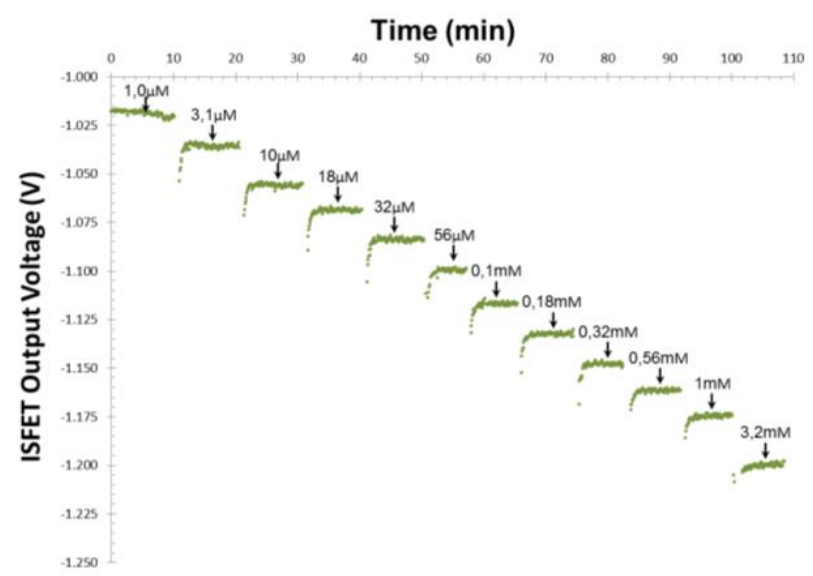

Figure 5: Analytical response of the $\mathrm{pNH}_{4}$-ISFET to the in

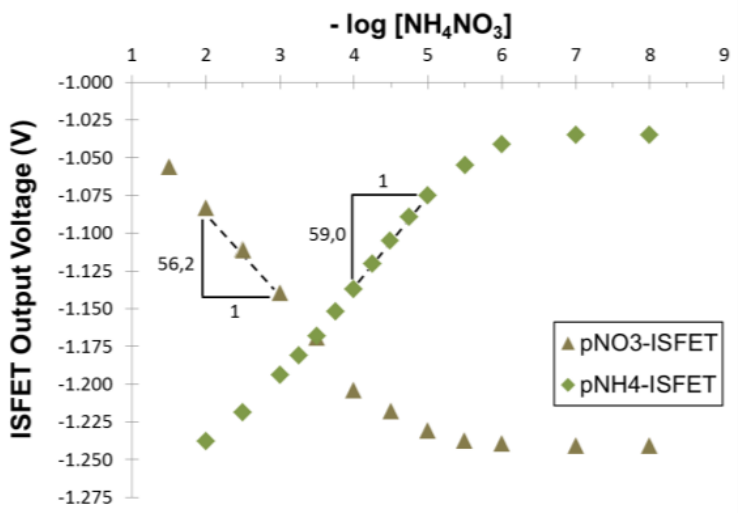

Figure 6: Calibration curves of the $\mathrm{PNO}_{3}$-ISFET and pNH $\mathrm{N}_{4}$ ISFET in aqueous solution of $\mathrm{NH}_{4} \mathrm{NO}_{3}$.

Table 2: Summary of the main electrochemical performances of $\mathrm{pNH}_{4}$-ISFET and $\mathrm{pNO}_{3}$-ISFET

\begin{tabular}{|c|c|c|}
\hline & $\mathbf{p N H 4}$ & $\mathbf{p N O 3}$ \\
\hline $\begin{array}{c}\text { Sensitivity } \\
\left(\mathbf{m} \mathbf{m} / \mathbf{p X} \mathbf{X}^{+/}\right)\end{array}$ & 59.0 & 56.2 \\
\hline $\begin{array}{c}\text { Detection limit } \\
(\boldsymbol{\mu M})\end{array}$ & 3.2 & 17 \\
\hline $\begin{array}{c}\text { Linear range } \\
\left(\mathbf{p X}^{+/}\right)\end{array}$ & {$[-2.5-4.5]$} & {$[-1.5-4.5]$} \\
\hline
\end{tabular}

A specific care was taken for the determination of FIM selectivity coefficient (Table 3) as direct measurements in soils could obviously not be done without the presence of interfering ions.

Regarding nitrate detection, we chose to use Nitrate Ionophore $\mathrm{V}$ as it displays the best selectivity coefficients reported so far for a commercially available ion exchanger [9]. Surprisingly, the relative responses of our $\mathrm{pNO}_{3}$-ISFET towards interfering ions indicate a strong Hofmeister behavior with a poor selectivity towards chloride. This result could be explained by the use of the FPSX matrix instead of the more conventional PVC. Indeed, fluoropolymers display lower polarity which does not facilitate the extraction of more lipophilic anions such as chloride. The use of a non-fluorinated siloxane may increase the selectivity of our sensors towards chloride while ensuring a good adhesion on the gate ISFET. In the other hand, fluorinated siloxanes are used on electrochemical sensors for antifouling strategies, an interesting property given the objective of our system [10]. Nevertheless, with exception to coastal soils in which high content in chloride is expected, our pNO3ISFET should be selective enough for an application to soil monitoring.

Overall our $\mathrm{pNH}_{4}$-ISFET exhibited really good selectivity coefficients towards the main cations likely to be found in soil. As expected with nonactin ionophore, potassium $\mathrm{K}^{+}$interfered the strongest but our ISFET showed a slight improvement of selectivity in comparison with most of the nonactin-based membrane reported [11].

Table 3: Selectivity coefficients $\left(\log K_{i j}\right)$ obtained with the Fixed Interference Method for $\mathrm{pNH}_{4-}$ and $\mathrm{pNO}_{3}$-ISFET. The constant concentration of interfering ion is indicated in brackets.

\begin{tabular}{|c|c|c|c|}
\hline $\begin{array}{c}\text { Interfering } \\
\text { ion }\end{array}$ & $\log \mathrm{K}_{\mathrm{NH}{ }^{+}, \mathrm{C}^{+}}$ & $\begin{array}{c}\text { Interfering } \\
\text { ion }\end{array}$ & $\log \mathrm{K}_{\mathrm{NO3}^{-},{ }^{-}}$ \\
\hline $\begin{array}{c}\mathbf{K}^{+} \\
(\mathbf{0 . 0 0 5 M})\end{array}$ & -1.2 & $\begin{array}{c}\mathrm{Cl}^{-} \\
(0.005 \mathrm{M})\end{array}$ & -1.6 \\
\hline $\begin{array}{c}\mathrm{Na}^{+} \\
(\mathbf{0 . 1 M})\end{array}$ & -3.0 & $\begin{array}{l}\mathrm{H}_{2} \mathrm{PO}_{4}^{-} \\
\left(0.05 M^{-}\right)\end{array}$ & -2.9 \\
\hline $\begin{array}{c}\mathrm{Ca}^{2+} \\
(0.05 \mathrm{M})\end{array}$ & -4.8 & $\begin{array}{l}\mathrm{PO}_{4}{ }^{3-} \\
(0.1 \mathrm{M})\end{array}$ & -4.0 \\
\hline $\begin{array}{c}\mathrm{Mg}^{2+} \\
(0.1 \mathrm{M})\end{array}$ & -5.0 & $\begin{array}{c}\mathrm{SO}_{4}{ }^{2-} \\
(0.1 \mathrm{M})\end{array}$ & -3.1 \\
\hline
\end{tabular}




\begin{tabular}{|c|l|c|c|}
\hline $\mathbf{L i}^{+}$ & -4.1 & $\mathbf{C H}_{3} \mathbf{C O O}^{-}$ & -2.5 \\
$(\mathbf{0 . 0 1 M})$ & $-101 \mathbf{M})$ & -2 \\
\hline
\end{tabular}

\section{In-situ detection of ammonium ions}

Finally, we tested our pNH4-ISFET in silty-clay soils of varying nitrogen content. Nitrogen mineralization is a process where the soil microbial population converts organic nitrogen to ammonium and nitrate forms. It is a temperature-dependent phenomenon. Thus, starting with two pots of the same soil, we obtained two distinct nitrogen content soil samples by putting them respectively at $38^{\circ} \mathrm{C}$ and $4^{\circ} \mathrm{C}$ for one month. Measurements performed into these soils directly after calibration allowed to discriminate the two levels of nitrogen. We successfully recorded an increase in ammonium concentration caused by the stimulation of nitrogen mineralization by soil microorganisms (fig.7).

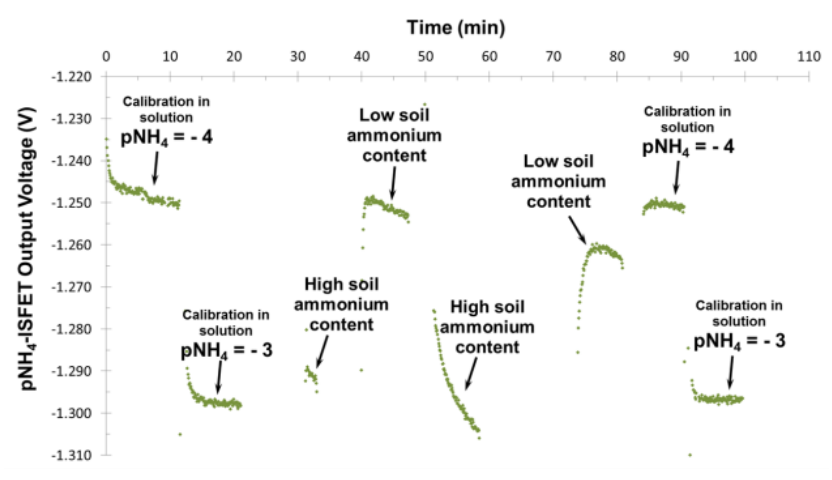

Figure 7: Plot vs Time of $\mathrm{pNH}_{4}$-ISFET signal. The measurements are first done in two calibration solutions, and then in high and low nitrogen content soils before being checked again in the two same calibration solutions.

\section{CONCLUSION}

Our pH-ISFET succeeded in measuring acidic and basic soils, for short and long periods of time, with only an elementary packaging and in avoiding the need for a time-consuming step of soil sampling. Thus, these results validated the feasibility of a direct measurement method in soil. Then, our nitrogen-functionalized ISFET exhibited quasi-Nernstian sensitivity and detection limit in accordance with standard values in field conditions. Using the same new method, our $\mathrm{pNH}_{4}$-ISFET showed promising results in being able to differentiate two soils of different nitrogen content. Overall, this work highlights the promising future of the ISFET technology for precision agriculture. Our work will now focus on multiplying the tests of functionalized ISFET in order to assess, in particular, the lifetime of the ion-sensitive membrane in real soil conditions.

\section{ACKNOWLEDGEMENTS}

This work was partly supported by LAAS-CNRS micro and nanotechnologies platform, member of the
French RENATECH network.

\section{REFERENCES}

[1] H.-J. Kim et al., "Soil macronutrient sensing for precision agriculture", Journal of Environmental Monitoring, vol. 11, p. 1810, 2009.

[2] U. Lehmann and A. Grisel, "Miniature Multisensor Probe for Soil Nutrient Monitoring", Procedia Engineering, vol. 87, p. 1429-1432, 2014.

[3] M. Futagawa et al., "A Miniature Integrated Multimodal Sensor for Measuring $\mathrm{pH}, \mathrm{EC}$ and Temperature for Precision Agriculture", Sensors (Basel), vol. 12, p. 8338-8354, 2012.

[4] J. Artigas et al., "Application of ion sensitive field effect transistor based sensors to soil analysis", Computers and electronics in agriculture, vol. 31, p. 281-293, 2001.

[5] P. Temple-Boyer et al., "Study of front-side connected chemical field effect transistor for water analysis ”, Microelectronics Reliability, vol. 44, no. 3, pp. 443-447, Mar. 2004.

[6] M. W. Shinwari et al., "Microfabricated Reference Electrodes and their Biosensing Applications", Sensors, vol. 10, no. 3, p. 1679-1715, 2010.

[7] A. Cazalé et al., "Study of field effect transistors for the sodium ion detection using fluoropolysiloxanebased sensitive layers", Sensors and Actuators B: Chemical, vol. B177, p. 515-521, 2013.

[8] R. P. Buck and E. Lindner, "Recommendations for nomenclature of Ion-Selective Electrodes", Pure \& Appl. Chem., vol. 66, p. 2527-2536, 1994.

[9] B. Paczosa-Bator et al., "Potentiometric Sensor Platform Based on a Carbon Black Modified Electrodes", Int. J. Electrochem. Sci., vol. 9, p. 28162823, 2014.

[10] A. Whelan and F. Regan, "Antifouling strategies for marine and riverine sensors", Journal of Environmental Monitoring, vol. 8, no. 9, p. 880-886, 2006.

[11] Y. Umezawa et al., "Potentiometric Selectivity Coefficients of Ion-Selective Electrodes. Part I. Inorganic Cations (Technical Report)", Pure and Applied Chemistry, vol. 72, no. 10, p. 1851-2082, 2000.

\section{CONTACT}

*J. Launay, tel: +33-5-61336809; jlaunay@laas.fr 